\title{
PENERAPAN MODEL UTAUT2 UNTUK MENGEVALUASI APLIKASI RUANG GURU
}

\author{
Celine Aloyshima Haris ${ }^{1}$, Bambang Soedijono WA ${ }^{2}$, Asro Nasiri ${ }^{3}$ \\ 1,2,3 Magister Teknik Informatika, Universitas AMIKOM Yogyakarta \\ Jl. Ring Road Utara, Kabupaten Sleman, Daerah Istimewa Yogyakarta \\ celine.haris@students.amikom.ac.id ${ }^{1}$, bambang.s@amikom.ac.id ${ }^{2}$, $\underline{\text { asro @ amikom.ac.id }}$
}

\begin{abstract}
Improving the quality of education by utilizing technology and the internet is currently very supported by the government starting from school and at the place of tutoring. Tutoring that utilizes technology and the internet is the Ruang Guru Application. In order to maximize the use and acceptance of the technology, in this research evaluating the Ruang Guru Application by using the Unified Theory of Acceptance and Use of Technology 2 (UTAUT2) model. The data in this research were obtained from questionnaire data distributed to 100 respondents of middle and high school students in Samarinda City. Based on the research results obtained variables that influence are performance expectations, effort expectations, social influence, facilitating condition, hedonic motivation, price value, habit, and facilitating condition moderated by age.
\end{abstract}

Keywords - Ruang Guru Application, Evaluation, UTAUT2.

\begin{abstract}
Peningkatan mutu pendidikan dengan memanfaatkan teknologi dan internet saat ini sangat didukung oleh pemerintah mulai dari disekolah dan ditempat bimbingan belajar. Bimbingan belajar yang memanfaatkan teknologi dan internet adalah Aplikasi Ruang Guru. Agar dapat memaksimalkan penggunaan dan penerimaan teknologi tersebut maka dalam penelitian ini mengevaluasi Aplikasi Ruang Guru dengan menggunakan model Unified Theory of Acceptance and Use of Technology 2 (UTAUT2). Data dalam penelitian ini didapatkan dari data kuesioner yang disebarkan kepada 100 responden siswa dan siswi SMP dan SMA di Kota Samarinda. Berdasarkan hasil penelitian diperoleh variabel yang mempengaruhi yaitu ekspektasi kinerja, ekpektasi usaha, faktor sosial, kondisi yang memfasilitasi, motivasi hedonis, nilai harga, kebiasaan, dan kondisi yang memfasilitasi dimoderasi oleh umur.
\end{abstract}

Kata kunci - Aplikasi Ruang Guru, Evaluasi, UTAUT2.

\section{PENDAHULUAN}

Pada saat sekarang ini bidang pendidikan sangat pesat berkembang seiring dengan kemajuan teknologi. Penggunaan internet diseluruh dunia juga meningkat disetiap harinya. Kemajuan teknologi dan penggunaan internet sangat berpengaruh terhadap dunia pendidikan, khususnya pendidikan di Indonesia. Dengan kemajuan tersebut, menuntut putra dan putri Indonesia untuk mempersiapkan diri dan memiliki bekal yang cukup untuk menjalani perubahan ke era digital dibidang pendidikan, agar tidak tertinggal dengan negara-negara lainnya.

Pendidikan yang diperoleh tidak hanya melalui pendidikan formal disekolah, melainkan dapat juga diperoleh melalui pendidikan non formal diluar sekolah seperti di tempat bimbingan belajar. Lembaga bimbingan belajar saat ini sudah banyak yang menerapkan penggunakan teknologi dan internet untuk menunjang kebutuhan sarana dan prasarananya. Salah satu lembaga bimbingan belajar yang telah menerapkan penggunakan teknologi yaitu aplikasi ruang guru yang dapat diakses melalui perangkat smartphone. Dengan kemajuan ini, pendidikan yang diperoleh dapat diakses dimana saja, kapan saja dan melalui perangkat apa saja termasuk perangkat smartphone dan laptop.

Model pemanfaatan dan peggunaan teknologi informasi yang digunakan dalam penelitian ini adalah model Unified Theory of Acceptance and Use of Technology 2 yang dikembangkan oleh Vankatesh, James Thong, dan Xin Xu pada tahun 2012. Dalam model ini, diperuntukkan untuk lebih menjelaskan dari perspektif konsumen selaku pengguna layanan berbasis teknologi informasi [1].

Dari uraian tersebut, maka peneliti mengambil judul penelitian "Penerapan Model UTAUT2 Untuk Mengevaluasi Aplikasi Ruang Guru”. Hasil dari penelitian ini diharapkan dapat mengetahui variabel yang berpengaruh dalam model penelitian yang diusulkan agar mendapatkan hasil evaluasi untuk mendukung aplikasi ruang guru yang lebih baik. 


\section{A. Aplikasi Mobile}

Aplikasi mobile adalah aplikasi yang dirancang khusus untuk sebuah platform mobile (seperti iOS, Android, atau Windows Mobile) [2]. Aplikasi mobile banyak digunakan untuk memudahkan masyarakat dari berbagai kalangan untuk menunjang aktifitas kehidupan sehari-hari. Terdapat beragam aplikasi mobile, seperti e-learning untuk menunjang pendidikan ada juga aplikasi bimbel online seperti aplikasi ruang guru, hingga aplikasi mobile untuk media sosial.

\section{B. Aplikasi Ruang Guru}

Aplikasi ruang guru adaah aplikasi mobile dibidang pendidikan non formal yang ada di Indonesia dan telah memperoleh Izin Pendirian Satuan Pendidikan Non Formal dan Izin Operasional Lembaga Kursus Pelatihan dengan Nomor 3/A.5a/31.74.01/1.851.332/2018 [3]. Hinggal saat ini aplikasi ruang guru telah memiliki lebih dari 6 juta pengguna serta berisikan 150.000 guru dengan lebih dari 100 bidang pelajaran. Contoh tampilan aplikasi ruang guru ditunjukkan pada Gambar 1.

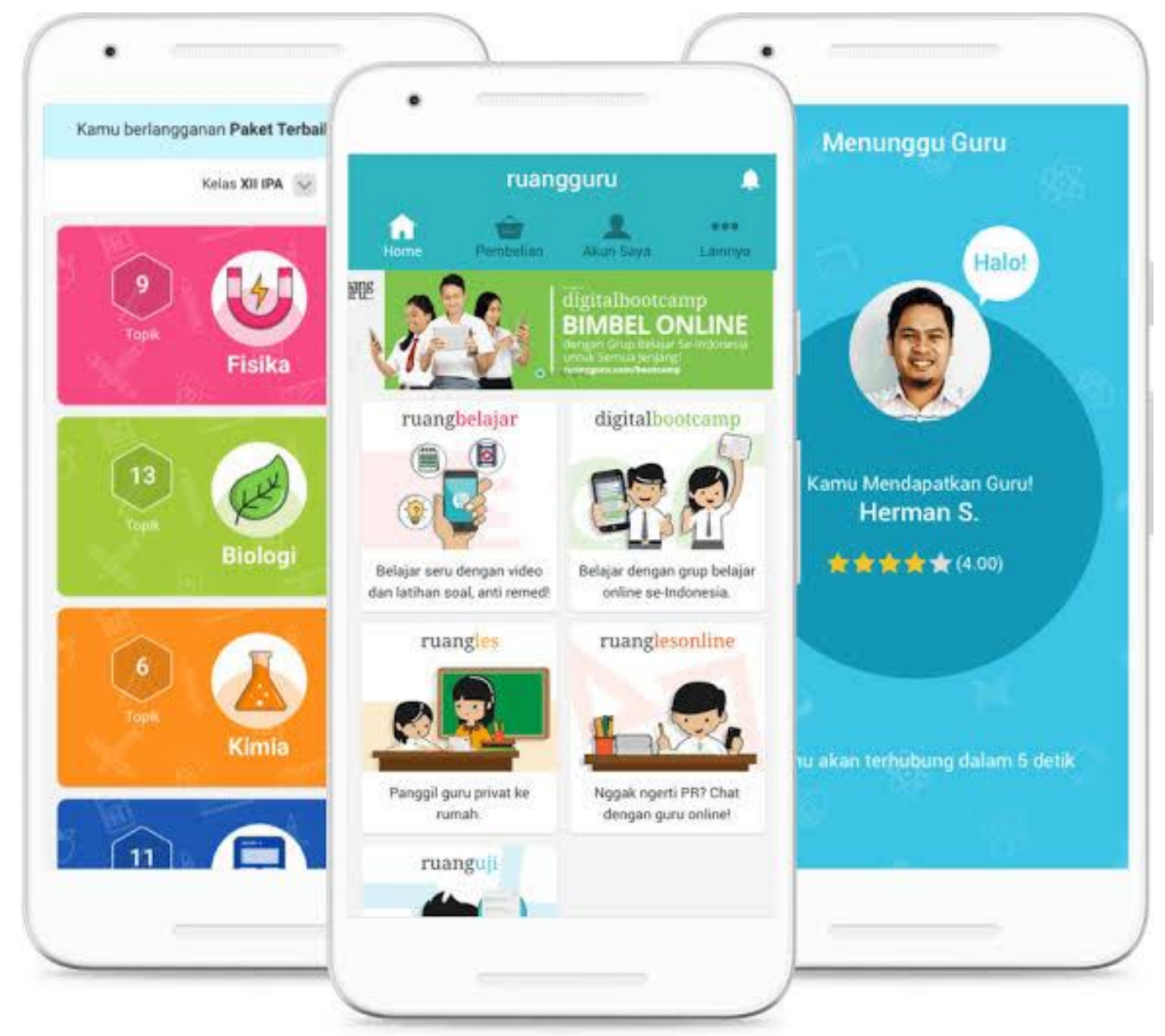

Gambar 1. Aplikasi Ruang Guru

Aplikasi Ruang Guru didiran oleh Belva Devara dan Isman Usman sejak tahun 2014. Aplkasi ini menawarkan berbagai produk, seperti Ruang Belajar, Ruang Les Online, Ruang Uji, Ruang Les, Ruang Kelas, Digital Boot Camp, Robo Guru, dan Ruang Baca. Aplikasi ini dapat diakses oleh berbagai jenjang pendidikan, mulai dari kelas 1 sampai kelas 6 Sekolah Dasar, kelas 7 sampai kelas 9 Sekolah Menengah Pertama, kelas 10 sampai 12 Sekolah Menengah Atas, hingga untuk persiapan Seleksi Bersama Masuk
Perguruan Tinggi Negeri (SBMPTN) dan Sekolah Tinggi Akuntansi Negara (STAN) juga tersedia.

\section{Model UTAUT2}

Model Unified Theory of Acceptance and Use of Technology 2 (UTAUT2) merupakan sebuag model yang disusun untuk mengetahui penerimaan dan penggunaan teknologi yang dikembangkan oleh Vankatesh, Tong, dan Xu pada tahun 2012. Dalam model UTAUT2 ini mengacu pada perilaku konsumen dalam penggunaan teknologi. Model UTAUT2 ditunjukkan pada Gambar 2. 


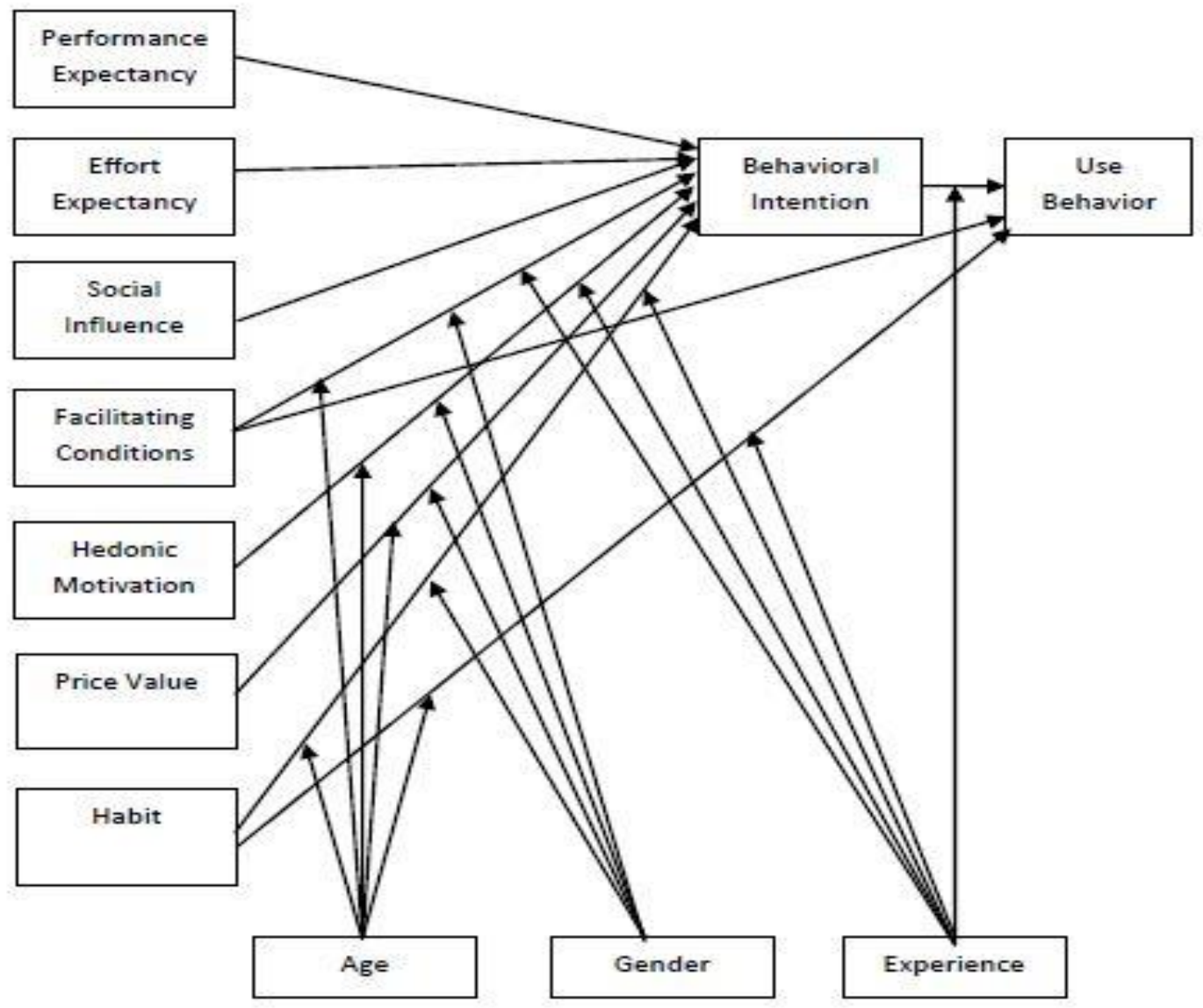

Gambar 2. Model UTAUT2 2012

Variabel utama dalam model ini yaitu ekspektasi kinerja (performance expectancy), ekspektasi usaha (effort expectancy), pengaruh sosial (social influence), kondisi fasilitas (facilitating condition), motivasi hedonis (hedonic motivation), nilai harga (price value), kebiasaan (habit), sikap terhadap penggunaan teknologi (behavioral intention), dan perilaku penggunaan teknologi (use behavior). Variabel moderasi dalam model ini yaitu umur (age), jenis kelamin (gender), dan pengalaman (experience) [1].

\section{Uji Korelasi Spearman's Rank}

Uji Korelasi Spearman's Rank ini digunakan untuk mengukur hubungan antara dua variabel dimana kedua variabel berbentuk peringkat (rank). Sebagai acuan kriteria penilaian korelasi, maka ditunjukkan pada Tabel 1 [4].

Tabel 1. Kriteria Penilaian Korelasi

\begin{tabular}{|c|c|}
\hline Interval Koefisien & Tingkat Hubungan \\
\hline $0,00-0,199$ & Sangat Lemah \\
\hline $0,20-0,399$ & Lemah \\
\hline $0,40-0,599$ & Sedang \\
\hline $0,60-0,799$ & Kuat \\
\hline $0,80-1,000$ & Sangat Kuat \\
\hline
\end{tabular}

Kriteria yang ditetapkan dengan membandingkan nilai thitung dengan tingkat signifikansi 0,05 (alpha $=$ 0,05). Jika $t_{\text {hitung }}<t_{\text {tabel}}$, maka Hipotesis diterima, begitupun sebaliknya. Kemudian menentukan tingkat hubungan korelasinya menggunakan kriteria penilaian pada Tabel 1.

\section{E. Uji Regresi Moderasi}

Uji Regresi Moderasi adalah pengujian untuk mengkaji hubungan antara beberapa variabel, yaitu variabel tidak bebas dengan adanya variabel moderasi [5]. Untuk mengetahui tiap hipotesis yang diusulkan diterima atau ditolak, maka nilai resiko kekeliruan yang diajukan sebesar 5\% (alpha $=5 \%)$. Jika nilai signifikansi Sig. $<0,05$ maka hipotesis diterima, begitupun sebaliknya. Kemudian menentukan tingkat hubungan korelasinya menggunakan kriteria penilaian pada Tabel 1

\section{METODE PENELITIAN}

Penelitian ini termasuk jenis penelitian eksplanatori, yaitu penelitian yang menjelaskan hubungan klausal antara variabel-variabel penelitian melalui pengujian hipotesis. Penelitian ini juga bersifat 
penelitian korelasional, yaitu penelitian yang membuktikan hubungan dari dua variabel atau lebih, dan sejauh mana derajat hubungan korelasinya.

1. Mengumpulkan Data

Penelitian ini dimulai dari mengumpulkan data, yang terdiri dari studi literatur berupa buku dan jurnal dan penelitian lapangan berupa penyebaran kuesioner.

2. Mengolah Data

Setelah mengumpulkan data diatas selesai selanjutnya dilakukan pengolahan data. Hal ini bertujuan untuk mengelolah data hasil kuesioner dengan pengujian validitas dan reliabilitas.

\section{Pengumpulan Data}

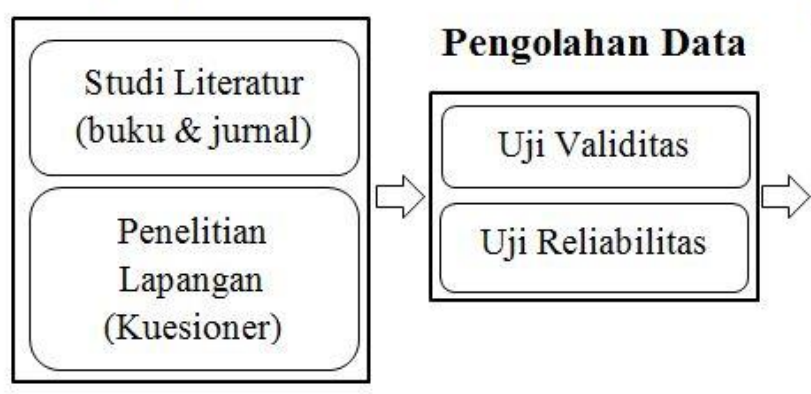

3. Pengujian Hipotesis

Tahap ini melakukan pengujian terhadap hipotesis yang diajukan menggunakan pengujian korelasi spearman's rank dan regresi moderasi.

4. Analisis Hasil dan Kesimpulan

Tahapan berikutnya yang akan dilakukan di dalam penelitian adalah melakukan analisis hasil dari pengujian dan menyimpulkan variabel yang berpengaruh serta nilai signifikansi dan tingkat korelasi antar variabel yang berpengaruh.

Gambar 3. Alur Penelitian

\section{A. Variabel dan Indikator}

Variabel dalam penelitian ini menggunakan 3 jenis variabel, yaitu variabel independen, variabel dependen, dan variabel moderasi. Variabel independen yaitu ekspektasi kinerja (performance expectancy), ekspektasi usaha (effort expectancy), pengaruh sosial (social influence), kondisi fasilitas (facilitating condition), motivasi hedonis (hedonic motivation), nilai harga (price value), dan kebiasaan (habit). Variabel dependen yaitu niat perilaku untuk menggunakan (behavioral intention to use). Variabel moderasi yaitu umur (age) dan jenis kelamin (gender).

Tabel 2. Variabel dan Indikator

\begin{tabular}{|c|l|l|}
\hline \multirow{4}{*}{$\begin{array}{c}\text { Verformance Expectancy } \\
\text { (PE) }\end{array}$} & \multicolumn{2}{|l|}{ Indikator } \\
\cline { 2 - 3 } & PE1 & Presepsi Pemanfaatan \\
\cline { 2 - 3 } & PE3 & $\begin{array}{l}\text { Meningkatkan } \\
\text { Efektivitas }\end{array}$ \\
\cline { 2 - 3 } & PE4 & $\begin{array}{l}\text { Produktivitas } \\
\text { memudahan } \\
\text { informasi }\end{array}$ \\
\hline \multirow{5}{*}{ Effort Expectancy (EE) } & EE1 & $\begin{array}{l}\text { Kemudahan } \\
\text { penggunaan }\end{array}$ \\
\cline { 2 - 3 } & EE2 & Kemudahan Interaksi \\
\cline { 2 - 3 } & EE3 & $\begin{array}{l}\text { Kemudahan untuk } \\
\text { dipelajari }\end{array}$ \\
\cline { 2 - 3 } & EE4 & $\begin{array}{l}\text { Kemudahan menjadi } \\
\text { ahli }\end{array}$ \\
\hline
\end{tabular}

\section{Pengujian Hipotesis}

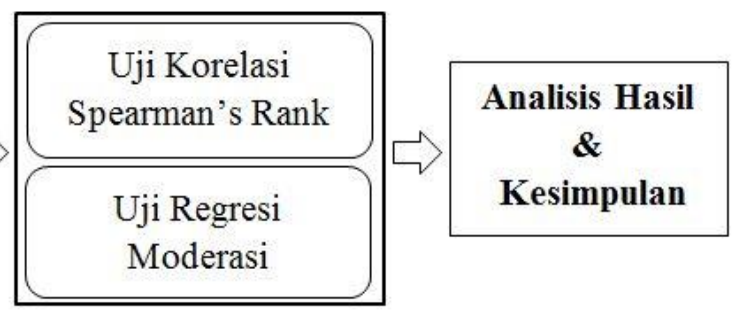

\begin{tabular}{|c|c|c|}
\hline \multirow{3}{*}{ Social Influence (SI) } & SI1 & $\begin{array}{l}\text { Faktor dukungan dari } \\
\text { orangtua }\end{array}$ \\
\hline & SI2 & Faktor teman sekolah \\
\hline & $\mathrm{SI} 3$ & $\begin{array}{l}\text { Faktor dukungan dari } \\
\text { orang yang } \\
\text { berpengaruh }\end{array}$ \\
\hline \multirow{3}{*}{$\begin{array}{l}\text { Facilitating Condition } \\
\text { (FC) }\end{array}$} & FC1 & $\begin{array}{l}\text { Kondisi internet yang } \\
\text { memfasilitasi }\end{array}$ \\
\hline & FC2 & $\begin{array}{l}\text { Perangkat yang } \\
\text { memadai }\end{array}$ \\
\hline & FC3 & Bantuan teknis \\
\hline \multirow{3}{*}{ Hedonic Motivation (HM) } & HM1 & Menyenangkan \\
\hline & HM2 & User Friendly \\
\hline & HM3 & Menarik \\
\hline \multirow{3}{*}{ Price Value (PV) } & PV1 & Harga Terjangkau \\
\hline & PV2 & Banyak Keuntungan \\
\hline & PV3 & Materi Tidak Terbatas \\
\hline \multirow{3}{*}{ Habit $(\mathrm{H})$} & $\mathrm{H} 1$ & Rutinitas \\
\hline & $\mathrm{H} 2$ & Kecanduan \\
\hline & $\mathrm{H} 3$ & Keharusan \\
\hline \multirow{2}{*}{$\begin{array}{c}\text { Behavioral Intention to } \\
\text { Use (BIUS) }\end{array}$} & BIUS1 & $\begin{array}{l}\text { Menggunakan lebih } \\
\text { sering }\end{array}$ \\
\hline & BIUS2 & $\begin{array}{l}\text { Menggunakan jangka } \\
\text { panjang }\end{array}$ \\
\hline \multirow{2}{*}{ Age (A) } & A1 & Anak-anak (SMP) \\
\hline & $\mathrm{A} 2$ & Remaja (SMA) \\
\hline \multirow{2}{*}{ Gender $(\mathrm{G})$} & G1 & Perempuan \\
\hline & G2 & Laki-laki \\
\hline
\end{tabular}

B. Model Penelitian

Model penelitian yang diajukan dalam penelitian ini ditunjukkan pada Gambar 3. 


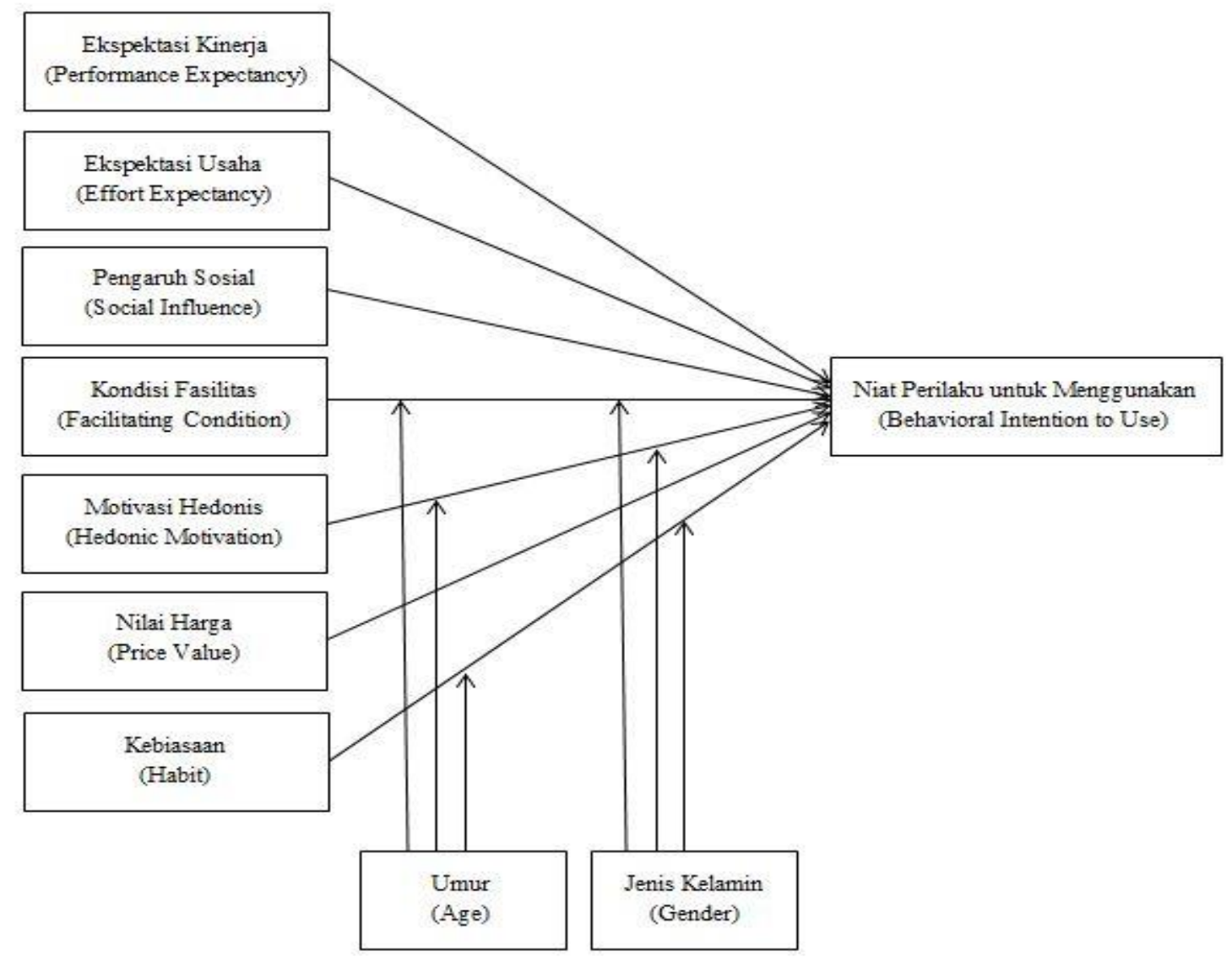

Gambar 4. Model Penelitian

\section{Hipotesis}

Hipotesis dalam penelitian ini adalah untuk menjelaskan variabel-variabel yang mempengaruhi penggunaan Aplikasi Ruang Guru yang ditunjukkan pada Tabel 3.

Tabel 3. Hipotesis

\begin{tabular}{|c|c|}
\hline No. & Hipotesis \\
\hline H1 & $\begin{array}{l}\text { Ekspektasi kinerja memiliki pengaruh terhadap niat } \\
\text { menggunakan aplikasi ruang guru. }\end{array}$ \\
\hline $\mathrm{H} 2$ & $\begin{array}{l}\text { Ekspektasi usaha memiliki pengaruh terhadap niat } \\
\text { menggunakan aplikasi ruang guru. }\end{array}$ \\
\hline $\mathrm{H} 3$ & $\begin{array}{l}\text { Faktor sosial memiliki pengaruh terhadap niat } \\
\text { menggunakan aplikasi ruang guru. }\end{array}$ \\
\hline $\mathrm{H} 4$ & $\begin{array}{l}\text { Kondisi yang memfasilitasi memiliki pengaruh } \\
\text { terhadap niat menggunakan aplikasi ruang guru. }\end{array}$ \\
\hline H5 & $\begin{array}{l}\text { Motivasi hedonis memiliki pengaruh terhadap niat } \\
\text { menggunakan aplikasi ruang guru. }\end{array}$ \\
\hline H6 & $\begin{array}{l}\text { Nilai harga memiliki pengaruh terhadap niat } \\
\text { menggunakan aplikasi ruang guru. }\end{array}$ \\
\hline H7 & $\begin{array}{l}\text { Kebiasaan memiliki pengaruh terhadap niat } \\
\text { menggunakan aplikasi ruang guru. }\end{array}$ \\
\hline $\mathrm{H} 8$ & $\begin{array}{l}\text { Kondisi yang memfasilitasi memiliki pengaruh } \\
\text { terhadap niat menggunakan aplikasi ruang guru yang } \\
\text { dimoderasi oleh umur. }\end{array}$ \\
\hline H9 & $\begin{array}{l}\text { Motivasi hedonis memiliki pengaruh terhadap niat } \\
\text { menggunakan aplikasi ruang guru yang dimoderasi } \\
\text { oleh umur. }\end{array}$ \\
\hline
\end{tabular}

\begin{tabular}{|c|l|}
\hline No. & \multicolumn{1}{|c|}{ Hipotesis } \\
\hline H10 & $\begin{array}{l}\text { Kebiasaan memiliki pengaruh terhadap niat } \\
\text { menggunakan aplikasi ruang guru yang dimoderasi } \\
\text { oleh umur. }\end{array}$ \\
\hline H11 & $\begin{array}{l}\text { Faktor sosial memiliki pengaruh terhadap niat } \\
\text { menggunakan aplikasi ruang guru yang dimoderasi } \\
\text { oleh jenis kelamin. }\end{array}$ \\
\hline H12 & $\begin{array}{l}\text { Motivasi hedonis memiliki pengaruh terhadap niat } \\
\text { menggunakan aplikasi ruang guru yang dimoderasi } \\
\text { oleh jenis kelamin. }\end{array}$ \\
\hline H13 & $\begin{array}{l}\text { Kebiasaan memiliki pengaruh terhadap niat } \\
\text { menggunakan aplikasi ruang guru yang dimoderasi } \\
\text { oleh jenis kelamin. }\end{array}$ \\
\hline
\end{tabular}

\section{HASIL DAN PEMBAHASAN}

Dari penelitian yang telah dilakukan dengan penyebaran 50 eksemplar kuesioner pada siswa dan siswi Sekolah Menengah Pertama (SMP) dan Sekolah Menengah Atas (SMA) di Kota Samarinda.

\section{A. Uji Validitas}

Kuesioner yang sudah didapatkan diolah menggunakan Statistical Package for Social Science (SPSS) versi 22 dengan pengujian validitas. Uji validitas dilakukan dengan membandingkan nilai $\mathrm{R}$ hitung dan R-Tabel, dalam peelitian ini jumlah sampel yang digunakan $(n)=100$ dan alpha $=0,05$ diperoleh $R$ - 
Tabel $=0,1966$. Semua variabel yang ditunjukkan pada Tabel 4 semuanya dinyatakan valid karena R-Hitung lebih besar dari R-Tabel.

Tabel 4. Hasil Uji Validitas

\begin{tabular}{|c|c|c|c|c|}
\hline Variabel & Indikator & R-Hitung & R-Tabel & Ket \\
\hline \multirow{4}{*}{ PE } & PE1 & 0,727 & 0,1966 & Valid \\
\hline & PE2 & 0,785 & 0,1966 & Valid \\
\hline & PE3 & 0,781 & 0,1966 & Valid \\
\hline & PE4 & 0,738 & 0,1966 & Valid \\
\hline \multirow{4}{*}{$\mathrm{EE}$} & EE1 & 0,606 & 0,1966 & Valid \\
\hline & EE2 & 0,720 & 0,1966 & Valid \\
\hline & EE3 & 0,642 & 0,1966 & Valid \\
\hline & EE4 & 0,776 & 0,1966 & Valid \\
\hline \multirow{3}{*}{ SI } & SI1 & 0,720 & 0,1966 & Valid \\
\hline & SI2 & 0,772 & 0,1966 & Valid \\
\hline & SI3 & 0,827 & 0,1966 & Valid \\
\hline \multirow{3}{*}{$\mathrm{FC}$} & $\mathrm{FC} 1$ & 0,873 & 0,1966 & Valid \\
\hline & $\mathrm{FC} 2$ & 0,617 & 0,1966 & Valid \\
\hline & $\mathrm{FC} 3$ & 0,789 & 0,1966 & Valid \\
\hline \multirow{3}{*}{ HM } & HM1 & 0,815 & 0,1966 & Valid \\
\hline & HM2 & 0,819 & 0,1966 & Valid \\
\hline & HM3 & 0,627 & 0,1966 & Valid \\
\hline \multirow{3}{*}{ PV } & PV1 & 0,940 & 0,1966 & Valid \\
\hline & PV2 & 0,578 & 0,1966 & Valid \\
\hline & PV3 & 0,937 & 0,1966 & Valid \\
\hline \multirow{3}{*}{$\mathrm{H}$} & H1 & 0,737 & 0,1966 & Valid \\
\hline & $\mathrm{H} 2$ & 0,717 & 0,1966 & Valid \\
\hline & $\mathrm{H} 3$ & 0,816 & 0,1966 & Valid \\
\hline \multirow{2}{*}{ BIUS } & BIUS1 & 0,901 & 0,1966 & Valid \\
\hline & BIUS2 & 0,836 & 0,1966 & Valid \\
\hline \multirow{2}{*}{ A } & A1 & 0,727 & 0,1966 & Valid \\
\hline & A2 & 0,851 & 0,1966 & Valid \\
\hline \multirow{2}{*}{ G } & G1 & 0,958 & 0,1966 & Valid \\
\hline & G2 & 0,939 & 0,1966 & Valid \\
\hline
\end{tabular}

\section{B. Uji Reliabilitas}

Uji reliabilitas dilakukan setelah semua variabel dinyatakan valid. Pengujian reliabilitas ini dilakukan dengan melihat nilai Cronbach Alpha >0,60. Semua variabel yang ditunjukkan pada Tabel 5 semuanya dinyatakan reliabel karena nilai Cronbach Alpha sudah lebih dari 0,60 sehingga semua variabel layak untuk digunakan.

Tabel 5. Hasil Uji Reliabilitas

\begin{tabular}{|c|c|c|}
\hline Variabel & Cronbach Alpha & Keterangan \\
\hline $\begin{array}{c}\text { Performance } \\
\text { Expectancy (PE) }\end{array}$ & 0,739 & Reliabel \\
\hline $\begin{array}{c}\text { Effort Expectancy } \\
\text { (EE) }\end{array}$ & 0,623 & Reliabel \\
\hline Social Influence (SI) & 0,664 & Reliabel \\
\hline $\begin{array}{c}\text { Facilitating Condition } \\
\text { (FC) }\end{array}$ & 0,627 & Reliabel \\
\hline $\begin{array}{c}\text { Hedonic Motivation } \\
\text { (HM) }\end{array}$ & 0,630 & Reliabel \\
\hline $\begin{array}{c}\text { Price Value (PV) } \\
\text { Habit (H) }\end{array}$ & 0,783 & Reliabel \\
\hline $\begin{array}{c}\text { Behavioral Intention } \\
\text { to Use (BIUS) }\end{array}$ & 0,641 & Reliabel \\
\hline Age (A) & 0,640 & Reliabel \\
\hline Gender (G) & 0,900 & \\
\hline
\end{tabular}

\section{Uji Hipotesis}

Dalam pengujian hipotesis $\mathrm{H} 1-\mathrm{H} 7$ menggunakan pengujian korelasi spearman's rank dan hipotesis H8H13 menggunakan pengujian regresi moderasi. Hasil uji hipotesis dapat dilihat pada Tabel 6 .

Tabel 6. Hasil Uji Hipotesis

\begin{tabular}{|c|c|c|c|c|}
\hline Hipotesis & $\begin{array}{c}\text { Nilai } \\
\text { Signifikansi }\end{array}$ & $\begin{array}{c}\text { Nilai } \\
\text { Korelasi }\end{array}$ & $\begin{array}{c}\text { Hubungan } \\
\text { Korelasi }\end{array}$ & Ket \\
\hline 1 & 0,000 & 0,451 & Sedang & Diterima \\
\hline 2 & 0,001 & 0,330 & Lemah & Diterima \\
\hline 3 & 0,002 & 0,311 & Lemah & Diterima \\
\hline 4 & 0,000 & 0,404 & Sedang & Diterima \\
\hline 5 & 0,000 & 0,398 & Lemah & Diterima \\
\hline 6 & 0,000 & 0,497 & Sedang & Diterima \\
\hline 7 & 0,001 & 0,323 & Lemah & Diterima \\
\hline 8 & 0,001 & 0,645 & Kuat & Diterima \\
\hline 9 & 0,090 & 0,506 & Sedang & Ditolak \\
\hline 10 & 0,560 & 0,498 & Sedang & Ditolak \\
\hline 11 & 0,520 & 0,583 & Sedang & Ditolak \\
\hline 12 & 0,827 & 0,484 & Sedang & Ditolak \\
\hline 13 & 0,903 & 0,628 & Kuat & Ditolak \\
\hline
\end{tabular}

D. Pembahasan

Dari hasil penelitian yang telah dilakukan, maka hipotesis yang diterima dan variabel yang berpengaruh dengan kategori hubungan korelasi sedang adalah ekspektasi kinerja (performance expectancy), kondisi yang memfasilitasi (facilitating conditions), dan nilai harga (price value). Hal ini juga didukung dengan penelitian [1][6][7] yang memproleh hasil yang sama salah satunya bahwa adanya pengaruh variabel ekspektasi kinerja karena aplikasi ruang guru ini sangat bermanfaat, dan dapat meningkatkan pembelajaran yang efektif dan produktif serta mudah dalam mendapatkan informasi terkait materi pembelajaran. Dan juga didukung dengan penelitian [1][8][9] yang memperoleh hasil sama salah satunya bahwa adanya pengaruh variabel nilai harga karena harga berperan dalam mempengaruhi individu untuk memanfaatkan 
suatu sistem. Serta harga yang ditawarkan dalam aplikasi ruang guru termasuk terjangkau dengan keuntungan dan materi pembelajaran yang didapatkan tidak terbatas jenajng pendidikan.

Sedangkan variabel yang berpengaruh dengan kategori hubungan korelasi yang kuat adalah kondisi yang memfasilitasi (facilitating conditions) yang dimoderasi umur (age) terhadap niat menggunakan aplikasi ruang guru (behavioral intention to use). Hal ini juga didukung dengan penelitian [10] yang memproleh hasil yang sama bahwa pengguna usia muda sangat menyukai aplikasi ruang guru dengan difasilitasi internet dan perangkat yang mendukung. Aplikasi ruang guru ini juga sebaiknya lebih bergaya modern dan sesuai dengan gaya anak muda masa kini serta tampilan yang lebih casual sehingga pengguna anak-anak sekolah nyaman menggunakan aplikasi ruang guru untuk belajar dalam waktu lama.

Untuk hipotesis yang diterima dan variabel yang berpengaruh dengan kategori hubungan korelasi lemah adalah ekspektasi usaha (effort expectancy), faktor sosial (social influence), motivasi hedonis (hedonic motivation), dan kebiasaan (habit). Hal ini juga didukung dengan penelitian [10] yang memproleh hasil yang sama bahwa variabel motivasi hedonis perlu ditingkatkan agar berpengaruh signifikan dengan kategori sedang atau kuat. Dengan lebih membuat aplikasi ruang guru yang lebih menyenangkan, user friendly, dan konten pembelajaran yang menarik agar siswa dan siswi lebih termotivasi lagi untuk menggunakan aplikasi ruang guru.

Terdapat hipotesis yang ditolak yaitu variabel motivasi hedonis (hedonic motivation) yang dimoderasi umur (age), kebiasaan (habit) yang dimoderasi umur (age), faktor sosial (social infleuence) yang dimoderasi jenis kelamin (gender), motivasi hedonis (hedonic motivation) yang dimoderasi jenis kelamin (gender), dan kebiasaan (habit) yang dimoderasi jenis kelamin (gender) terhadap niat menggunakan aplikasi ruang guru (behavioral intention to use). Hal ini juga didukung dengan penelitian [11][12], salah satunya variabel faktor sosial tidak dimoderasi jenis kelamin karena dalam dukungan sosial yang diperoleh tidak memandang perbedaan jenis kelamin melainkan dari bentuk dukungan tersebut.

\section{KESIMPULAN}

Berdasarkan hasil penelitian, maka dapat diambil kesimpulan sebagai berikut :

1. Variabel yang sangat berpengaruh dalam penerapan model UTAUT2 untuk mengevaluasi Aplikasi Ruang Guru adalah variabel kondisi yang memfasilitasi dengan dimoderasi umur dengan nilai signifikansi 0,001 dan nilai korelasi 0,645, hal tersebut menyakan bahwa hubungan korelasinya kuat.
2. Variabel yang berpengaruh dengan hubungan korelasi yang sedang dalam penerapan model UTAUT2 untuk mengevaluasi Aplikasi Ruang Guru adalah variabel ekspektasi kinerja, kondisi yang memfasilitasi, dan nilai harga.

3. Variabel yang ditolak dalam penerapan model UTAUT2 untuk mengevaluasi Aplikasi Ruang Guru adalah variabel motivasi hedonis yang dimoderasi umur, kebiasaan yang dimoderasi umur, faktor sosial yang dimoderasi jeni kelamin, motivasi hedonis yang dimoderasi jenis kelamin, dan kebiasaan yan dimoderasi jenis kelamin.

\section{DAFTAR PUSTAKA}

[1] Venkatesh, V., Thong, J. Y., \& Xu, X. (2012). Consumer Acceptance and Use of Information Technology: Extending The Unified Theory of Acceptance and Use of Technology. MIS Quarterly, Vol. 36, No. 1, 157-178

[2] Pressman, R., \& Bruce, R. (2015). Software Engineering: A Practitioner's Approach 8th Edition. New York: McGaw-Hill Education

[3] Ruangguru. (2019). Ruang Guru. Retrieved Oktober 2019, from ruangguru.com: https://ruangguru.com/general/about

[4] Sugiyono. (2013). Metode Penelitian Kuantitaif, Kualitatif, dan $R \& D$. Bandung: Alfabeta

[5] Kutner, M., Nachtsheim, C., \& Neter, J. (2004). Applied Linear Regression Models 4th. New York: McGraw-Hill Companies

[6] Venkatesh, V., Moris, M., Davis, G., \& Davis, F. (2003). User Acceptance of Infomation Technology: Toward Unified of View. MIS Quarterly, Vol.27 No.3, Hal. 425-478.

[7] Prasetyo, D. Y. (2017). Penerapan Metode UTAUT Dalam Memahami Penerimaan Dan Penggunaan Website KKN LPPM UNISI. Jurnal Sistemasi Vol.6 No.2, 26-34.

Marhaeni, Gusti. 2014. "Analisis Perilaku Penggunaan Aplikasi Pesan Instan dengan Menggunakan Model Unified Theory of Acceptance and Use of Technology 2 di Kota Bandung". Thesis, Telkom University.

[9] Primasari, Nadia. 2015. Analisis Adopsi Media Advertising Digital Menggunakan Model Modified Unified Theory of Acceptance and Use of Technology 2 (Case Study: Layanan UAd Untuk Industri Consumer Goods Di Indonesia). Tesis. Bandung: Universitas 
Telkom.

[10] Putra, G., \& Ariyanti, M. (2013). Pengaruh Faktor-Faktor Dalam Modified Unified Theory of Acceptance and Use of The Technology 2 (UTAUT2) Terhadap Niat Prospective Users Untuk Mengadopsi Home Digital Services PT. Telkom Di Surabaya. Jurnal Manajemen Indoensia, 59-76.

[11] Mentaya, A., Sunarto, M. D., \& Wulandari, S. H. (2015). Faktor-Faktor Yang Berpengaruh Terhadap Penerimaan Aplikasi Brilian Dengan Model UTAUT. Jurnal Sistem Informasi dan Komputer Akuntansi, Vol.4 No.2.

[12] Merhi, M., Hone, K., \& Tarhini, A. (2019). A cross-cultural study of the intention to use mobile banking between lebanese and british consumers: extending UTAUT2 with security, privacy, and trust. Journal Technology in Society. 